\title{
COMPARISONS OF RECOGNITION CAPABILITIES AND PREFERENCES FOR REPRESENTATIONAL, ABSTRACT, AND NON-OBJECTIVE PAINTINGS
}

\section{Kerry Freedman}

Problems of art education can be illuminated by research in experimental psychology. Psychological studies of memory and artistic style can provide insights into the ways in which people recognize and give preference to art objects. In this essay, I will discuss some of these research approaches, and a study that incorporates their findings, as a way to consider choices in art curriculum.

\section{Human Memory and Pictorial Stimuli}

Humans appear to have a very large memory capacity for pictures (Haber, 1970; Nickerson, 1968; Shepard, 1967; Standing, Conezio, $\&$ Haber, 1970) and pictures are remembered better than chance even after a year (FajnstzejnPollack, 1973; Nickerson, 1968). However, the type of pictorial content seems to influence memory capabilities. For example, pictures of faces are remembered longer than pictures of landscapes (Deffenbacher, Carr, $\varepsilon$ Leu, 1981). It has been suggested through neural-physiological studies that the processing of faces takes place in a different part of the brain than the processing of other types of pictorial information (e.g. Carey \& Diamond, 1977).

The relationship between objects within pictures has further effects on memory. When objects in a picture are positioned in a realistic and meaningful manner, they are remembered very well. However, pictures with objects placed in a disoriented or non-interacting fashion are remembered close to chance, even though the objects themselves are retained (Mandler $\&$ Parker, 1976; Mandler $\varepsilon$ Ritchey, 1977; McKoon, 1981).

Dirks and Neisser's (1977), Hoffman and Dirks' (1976), and Mandler and Stein's (1974) work in picture memory has led to a new view of the influence of pictorial dimensions on recognition. These studies have indicated that recognition improves with age and that the type of pictorial dimensions tested influence responses.

A number of studies have supported the concept that children's abilities for encoding and decoding information become more effective as they develop. Capacities in short term memory which holds information to be transferred to long term memory, has been shown to improve with age. Results have shown that this occurs even in studies involving stimuli that are simple and very familiar (Boswell, 1976; Finkel, 1973; Haith, Morrison, Sheingold, \& Minders, 1970; Morrison \& Haith, 1976).

Some research has suggested that familiarity is the major influence in recognition capabilities (Kintsch, 1970). A pilot study I have done using representational, abstract and non-objective paintings indicated that stimulus dimensions (structural and those relating to representation) affect recognition as well (Note 1). 
Regardless of the contextual definition of information, human information processing begins as a perceptual experience and results in the transformation necessary for the coding of a new concept or an addition to one previously contained in abstract memory. Rowe (1974) makes a distinction between two predominant views of concept formation. The behaviorist view operationally defines concept learning as the capacity to categorize objects that have distinguishable differences. Rowe's perceptual-cognitive perspective, in contrast, describes a concept as the result of processing a combination of meanings and symbols. The fundamental principle underlying both of these definitions is the representation in memory of a group of dimensions and their relations.

The realm of concepts according to Potter (1979), involves cognitive and neural processing that causes information about an object or event to become available to consciousness. In her conceptual coding model for pictures and words, concepts are considered primal.

The development of the concept of artistic style has been studied from both the behaviorist and the perceptual-cognitive perspectives. Gardner and Gardner (1973) have resolved that the ability to sort art stimuli by style emerges spontaneously during adolescence, but can be taught at a much younger age given many prototypical examples. This research also indicates that children sort by the meaning of the subject matter rather than its shape or form. These researchers contend that their results show that verbal and cultural concepts are more influential than perceptual features.

There have been a number of conflicting reports concerning at exactly what developmental level the apprehension of style occurs, at what level it can be taught, and how it can best be taught (Bengston, Schoeller, $\mathcal{E}$ Cohen, 1978; Rush, 1979; Taylor $\&$ Trujilo, 1973; Tighe, 1968; Walk, Karusaitas, Lebowitz, \& Falbo, 1971). However, these and other studies (Clark, 1973; Fretchling $\varepsilon$ Davidson, 1970; Hartley $\&$ Homa, 1981; Walk, 1967) agree that the more prototypical examples that are shown to subjects, the more easily they are able to discriminate artistic style, and that this appears to be the case for most age groups.

Kenney and Nodine (1979) have evaluated sorting tendencies by their deep structure and surface structure qualities. Young children tend to use surface structure cues for sorting, while older subjects sorted by deep structural qualities, which include affective aspects and style. Gardner (1973) contends that color and texture are used by subjects as visual cues when determining style differences.

Gardner $(1970,1972)$ has also concluded that style sensitivity is the result of cognitive processing and that it is related to cultural awareness, which includes familiarity. DePorter and Kavanaugh (1978) support these hypotheses and suggest that style apprehension involves two developmental influences: (a) the developing perceptual abilities of the child, such as the emergence from centration, and (b) cultural and aesthetic experiences that are pertinent to style and perception. Although, as Hochberg and Brooks (1962) have shown, pictorial recognition of an object from a line drawing or photograph is not a

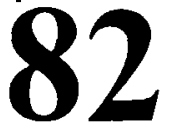


learned trait, there are indications that some individual components of style are learned. For example, studies have shown that some pictorial spatial representations are not understood cross-culturally (e.g. Deregowski, 1972).

Forming a concept of artistic style involves an understanding of abstraction. In art, style is often defined, in part, by the degree of representation of an aesthetic object. According to the 1974 Report of the Conference on Visual Information Processing Research and Technology organized by the National Institute of Education, it has not yet been determined how abstract is too abstract for children to see and understand an image as compared to adult capabilities. However, this group has reported that there are some similarities in the visual perception patterns of adults and children when familiar objects are viewed. This report states that when presented with familiar objects, children's eye movements patterns resemble those of adults. It has also been discovered that adults process certain abstractions, such as cartoonlike line drawings of objects, more quickly and easily than more representational drawings and photographs of the same objects (Ryan $\varepsilon$ Schwartz, 1955).

In light of this psychological research, questions can be asked concerning decisions made in the development of art curriculum. A study is currently underway that is an effort to further understand preference for and memory of paintings by three groups of subjects: art professors and graduate students in art, art student teachers and public school art teachers, and undergraduate non-art majors with no appreciable art training. Two experiments will utilize these same groups of subjects. The first requires the subjects to rate the stimulus paintings in terms of preference and on levels of abstraction and complexity. The second experiment is a recognition task that requires the subjects to attempt to correctly match paintings to the original sample. The stimuli for these experiments are unfamiliar paintings of varied artistic style (representational, abstract, and non-objective). It is hypothesized that comparisons between the paintings and the subject groups will further illuminate questions concerning art education.

\section{REFERENCES}

Benston, J.K., Schoeller, J., \& Cohen, S.J., (1978). On conceptualizing an artistic style: How critical are examples? Studies in Art Education, 20 (1), 49-55.

Boswell, S., (1976). Young children's processing of asymmetrical and symmetrical patterns. Journal of Experimental Child Psychology, 22, 309-318.

Carey, S., $\varepsilon$ Dimond, R. (1977). From piecemeal to configurational representation of faces. Science, $195,312-314$.

Clark, G.A. (1973). Analyzing iconic learning in the visual arts. Studies in Art Education, 14(3), 35-47.

Deffenbacher, K.A., Carr, T.H., E Leu, J.R. (1981). Memory for words, pictures, and faces: Retroactive interference, forgetting, and reminiscence. Journal of Experimental Psychology: Human Learning and Memory I (4), 299-305.

DePorter, D.A., \& Kavanaugh, R.D. (1978). Parameters of children's sensitivity to painting styles. Studies in Art Education, 20 (1), 43-48.

Deregowski, J.B. (November, 1982). Pictorial perception and culture. Scientific America. 
Dirks, J., E Neisser, U. (1977). Memory of objects in real scenes: The development of recognition and recall. Journal of Experimental Child Psychology, 23, 315-328.

Fajnstzejn-Pollack, G. (1973). A developmental study of decay rate in longterm memory. Journal of Experimental Child Psvchology, 15, 225-235.

Finkel, D. (1973). A developmental comparison of the processing of two types of visual information. Journal of Experimental Child Psychology 16, 250-266.

Fretchling, J.A. E Davidson, P.W. (1970). The development of the concept of artistic style: A free classification study. Psychonomic Science, 18, 79-80.

Gardner, H. (1970). Children's sensitivity to painting styles. Child Development, 41, 813-821.

Gardner, H. (1972). The development of sensitivity to figural and stylistic aspects of paintings. British Journal of Psychology 63, 605-615.

Gardner, H. (1973). The contribution of color and texture to the detection of paintings. Studies in Art Education, 15 (3), 57-62.

Gardner, H., \& Gardner, J. (1973). Developmental trends in sensitivity to form and subject matter in paintings. Studies in Art Education, 14 (2), 52-56.

Haber, R.N. (1970). How we remember what we see. Scientific American, 222 (5), 104-112.

Haith, M.M., Morrison, F., Sheingold, K., \& Minders, P., (1970). Shortterm memory for visual information in children and adults. Journal of Experimental Child Psychology 9, 454-469.

Hartley, J., \& Homa, D. (1981). Abstraction of stylistic concepts. Journal of Experimental Psychology: Human Learning and Memory, $\mathbf{I}$ (1), 33-46.

Hochberg, J., $\varepsilon$ Brooks, V. (1962). Pictorial recognition as an unlearned ability: A study of one child's performance. American Journal of Psychology 75 , 624-628.

Hoffman, C., \& Dirks,S. (1976). A developmental investigation of recognition memory. Child Development, 47, 749-799.

Kenney, J.L., $\varepsilon$ Nodine, C.F. (1979). Developmental changes in sensitivity to the content, formal, and affective dimensions of paintings. Bulletin of the Psychonomic Society, 14 (6), 463-466.

Kintsch, W. (1970). Learning memory and conceptual processes. New York: Wiley.

Mandler, J.M., \& Parker, R.E. (1976). Memory for descriptive and spatial information in complex pictures. Journal of Experimental Psychology: Human Learning and Memory, 2, 38-48.

Mandler, J.M. E Ritchey, G.H. (1977). Long-term memory for pictures. Journal of Experimenal Psychology: Human Learning and Memory, 3 (4), 386-396.

Mandler, J.M., \& Stein, N.L. Recall and recognition of pictures by children as a function of organization and distractor similarity. Journal of Experimental Psychology, 102, 657-669.

McKoon, G. (1981). The representation of pictures in memory. Journal of Experimental Psychology: Human Learning and Memory, $\underline{7}$ (3), 216-221.

Morrison, F., \& Haith, M. (1976). Recognition versus recall of briefly presented visual information: A developmental study. Journal of Experimental Child Psychology, 21, 191-200.

Nickerson, R.S. (1968). A note on long-term recognition memory for pictorial material. Psychonomic Science, $11,58$.

Potter, M. (1979). Mundane symbolism: The relations among objects, names and ideas. In N.R. Smith \& M.B. Franklin (Eds.), Symbolicfunctioning in childhood. Hillsdale, N.M.: L. Erlbaum, Assoc., 41-65.

Rowe, B.L. (1974-1975). Theoretical concept learning in art education. Studies in

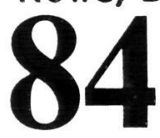


Art Education, 16 (1), 18-25.

Rush, J.C. (1979). Acquiring a concept of painting style. Studies in Art Education, 20 (3), 43-51.

Ryan, T.A., E Schwartz, C.B. (1955). Speed of perception as a function of mode of representation. Location unknown.

Shepard, R.N. (1967). Recognition memory for wrods, sentences, and pictures. Journal of Verbal Learning and Verbal Behavior, 6, 165-163.

Standing, L., Conezio, J., \& Haber, R.N., (1970). Perception and memory for pictures: Single trial learning of 2500 visual stimuli. Psychonomic Science, $19,73-74$.

Taylor, A.P. \& Trujilo, J.L. The effects of selected simuli on the art products, concept formation, and aesthetic judgment decisions of four-year-old children. Studies in Art Education, 14 (2), 57-66.

Tighe, T. (1968). Concepts formation and art: Further evidence on the applicability of Walk's technique. Psychonomic Science, 12, 363-364.

Walk, R. (1967). Concept formation and art: Basic experiment and controls. Psychonomic Science, 9, 237-238.

Walk, R., Karusaitis, K., Lebowitz, C., \& Falbo, R. (19711. Artistic style as concept formation for children and adults. Merrill-Palmer Quarterly of Behavior and Development, 17, 347-356.

\section{REFERENCE NOTES}

1. Freedman, K.J. The conceptual coding of art stimuli. Paper presented at the National Symposium for Research in Art, Urbana, September, 1982. 